\title{
ÉTICA É LIMITE
}

ETHICS MEANS LIMITS

Bianca Antunes Cortes 1

Resumo $\mathrm{O}$ presente ensaio põe em destaque as relações existentes entre conhecimento, poder e ética. No início de um novo milênio, não são poucas as implicações decorrentes das conquistas no campo das ciências da vida, cujas repercussões se refletem no cotidiano de trabalho dos profissionais de saúde e atualizam a interrogação quanto ao que é ou que não é 'bom' para o homem. Na trajetória da humanidade, a vida (do próprio homem, da natureza e dos outros seres não pertencentes à espécie humana) marca o motivo e o objetivo do conhecimento. No contexto das biotecnologias, coloca-se uma pergunta: em que medida estamos nos distanciando daquele motivo primeiro? Três autores se destacam, neste ensaio, na busca por uma resposta: Martin Buber, Hans Jonas e Emmanuel Lévinas. Eu e Tu, O principio da responsabilidade e Humanismo do outro homem são obras que afirmam a 'alteridade' como motivo da ética. 'A presença do outro' é o que funda o encontro ético. O encontro com o 'diferente de mim' inaugura o 'ato de conhecer' e a ética.

Palavras-chave ética; responsabilidade; alteridade; conhecimento, poder e ética; ética e ciência.
Abstract The present essay focuses on the relationship between knowledge, power and ethics. At the start of a new millennium, many are the implications of the achievements in the sciences of life, as the repercussions of these achievements have consequences for the health professionals' everyday work and bring up to date the doubts on what is or is not 'good' for the human being. In mankind's trajectory, life (of the human being, of nature and of other beings not belonging to the human species) is the motive and the objective of learning. In the biotechnological context, we ask: to what extent are we distancing ourselves from this primary motive? In seeking an answer for this question, this essay, looks, in particular, at the work of Martin Buber, Hans Jonas and Emmanuel Lévinas. Eu e Tu, O princípio da responsabilidade and Humanismo do outro homem are works in which the 'alterity' is considered to be the motive of ethics. 'The other's presence' is the basis for the ethical encounter. The encounter with that which is 'different from me' initiates the 'act of knowing' and ethics.

Key words ethics; responsibility; alterity; knowledge, power and ethics; ethics and science. 


\section{Introdução}

São incontestes as marcas que o discurso das certezas de si do sujeito cartesiano deixam na mentalidade ocidental. Certezas afirmadas pelo 'ato de duvidar' abriram um leque de questionamentos possíveis, que poderíamos sintetizar numa pergunta: em que termos pode ser estabelecida a relação entre sujeito e objeto?

A física, já no início do século $\mathrm{XX}$, redefiniu muitos dos termos desta relação. Ou seja, o século XX recebeu e respondeu de forma surpreendente à herança deixada em forma de interrogações e desafios pelos mil e oitocentos. Da mesma forma, o século que se inicia é herdeiro de questionamentos deixados pelo século anterior, exceto que, hoje, os termos da relação dizem respeito a um tipo de conhecimento cuja marca distintiva é tomar por 'objeto' o próprio 'sujeito'. Ou seja, um conhecimento que é marcado, muitas vezes, pela possibilidade, pelo objetivo, de inter-ferir em características que, até então, considerávamos distintivas do 'ser humano'.

Poucas não são as implicações decorrentes dessas conquistas no campo das ciências da vida, cujas repercussões se refletem no cotidiano de trabalho dos profissionais de saúde e atualizam a interrogação quanto ao que é ou não é 'bom' para o homem. Por óbvio que seja, não é demasiado destacar que tais conquistas não são o resultado de uma força inelutável do destino; foram construídas e trilhadas por atos humanos, num percurso marcado por uma incurável e insaciável curiosidade diante dos mistérios da vida, e de algum modo cristalizadas nos testemunhos das diferentes manifestações culturais. A técnica, em suas diferentes modalidades, é o que mediatiza os termos da relação que se estabelece entre o homem e a natureza. Um hipotético homem desprovido de qualquer aptidão técnica não sobreviveria um só dia. A técnica é, em última instância, uma forma de relação que se traduz em intervenção.

Esse reconhecimento não facilita a tarefa de falar de limite num cenário em que nossos modernos atos tecnológicos encurtam enormemente as distâncias entre o 'pensar' e o 'fazer'. Conhecimento, hoje, é sinônimo de conhecimento-ato. Como falar de ética, de limite, quando duas, pelo menos duas, de nossas balizas de referência estão sujeitas a diferentes possibilidades de interpretação? Nascimento e morte: sempre e desde sempre, estes eventos demarcam as fronteiras em que transcorre a existência humana. Todavia, nos últimos anos, deslocaram-se os limites, modificaram-se, prática e conceitualmente o que até então estava estabelecido como momentos de início e término da vida humana ${ }^{2}$.

A extensão dos poderes efetivados na tecnociência contemporânea se realiza num relativo vácuo ético ou, no mínimo, numa situação onde não se logra efetivar consensos sobre a demarcação de limites para o que devemos e 
não devemos fazer e saber. Estabelecer tais limites é tarefa especialmente difícil se considerarmos as características estruturais das sociedades da modernidade contemporânea, cujas regras de organização são construídas sob a valorização de um discurso de defesa da pluralidade.

Uma sociedade moderna é, tipicamente, uma sociedade pluralista. O que não necessariamente significa que tenhamos conseguido aumentar nossa capacidade de respeitar 'o diferente', 'o outro', 'o não-eu', pois tolerância não é sinônimo de respeito ${ }^{3}$. Nossas regras de convivência social são estabelecidas pelo 'princípio da pluralidade'. As sociedades plurais são marcadas pelo confronto permanente entre diferentes cosmovisões e pela presença de diferentes interpretações morais. Inegavelmente, a possibilidade de argumentar e interpretar a realidade sob diferentes prismas é uma das faces positivas das sociedades plurais. Mas se algo caracteriza de forma incisiva o mundo atual é, sem dúvida, a desproporção entre a velocidade do progresso científico-tecnológico e a lenta capacidade de resposta ética, fruto do vácuo ético que veio a ser formado a partir da desestruturação dos sistemas sociais fundados em valores tradicionais.

Nas sociedades ocidentais, de forma prevalecente, a tecitura do modo de organização da vida entrelaçou uma forma muito particular de produção e comercialização de bens materiais e de serviços, com um determinado modo de conhecer a natureza e explicar as relações inter-humanas. Sociedades industrializadas e conhecimento científico tecnológico são expressões que traduzem os êxitos e os descaminhos de um determinado modo de compreensão, comunicação, intervenção e organização da vida humana em sociedade. Nesse entrelaçamento, no dizer de Hannah Arendt, "não somente a natureza, que o homo faber vê como material quase 'sem valor' sobre o qual ele trabalha, mas até mesmo as coisas 'valiosas' tornam-se simples meios e, com isso, perdem o seu próprio 'valor' intrínseco" (Arendt, 1991, p. 168).

A ética não é uma das tantas técnicas que nos permitem inter-ferir na vida. A ética, quaisquer que sejam os adjetivos que se lhe agreguem, está sempre referida ao reconhecimento de limites às possibilidades. A idéia de que o possível não se autolegitima pertence à essência do agir ético, que pertence às entranhas do próprio ato de filosofar. Nesse sentido, ética é limite. Mas não só isso. A ética está originariamente ligada à noção da possibilidade de se definir o bem, quer como algo que é uma realidade perfeita, quer como objeto de desejo ou de aspiração. No primeiro caso, ela é compreendida como a ciência do fim a que a conduta humana deve, por sua essência, dirigir-se, o ideal a que o homem deve, por sua natureza, ser voltado. No segundo, ela é compreendida como a ciência do 'móvel' da conduta humana. $\mathrm{O}$ esforço por defini-lo se imbrica na própria necessidade de disciplinar essa conduta. O campo da ética se entende então como a esfera das causas do agir humano, das forças determinantes dos cursos desse agir. 
O termo ethos é a transliteração de duas palavras gregas. A primeira é ethos com letra inicial eta, a segunda é ethos com letra inicial épsilon. O ethos-eta designa a morada do homem, a casa, o lugar permanente de abrigo e proteção. É a partir do ethos-eta que o mundo se torna humanamente habitável: a physis é rompida pela abertura do ethos-eta, como um espaço construído e incessantemente reconstruído. O ethos-épsilon designa o comportamento que ocorre repetidas vezes; refere-se à gênese do hábito. Expressa uma oposição entre o que é 'habitual' e o que é 'natural'; nesse sentido diz respeito à disposição permanente do agente para agir de acordo com a realização do bem. Nas palavras de Henrique Cláudio de Lima Vaz, o ethos "rompe com a sucessão do 'mesmo' que caracteriza a physis como domínio da necessidade, com o advento do 'diferente' no espaço da liberdade aberta pela praxis" (Vaz, 1998, p.11).

O ethos é o lugar privilegiado da praxis. É a instância cultural que, na sua circularidade dialética, articula o âmbito social e universal cultural, a ordem da ação e o âmbito individual. O espaço humano do ethos não é dado; é permanentemente construído na interação dialética de suas instâncias. Esse movimento circular não está marcado por qualquer determinismo; o movimento do ethos, indo da universalidade do costume à singularidade da ação eticamente boa, traz em si a possibilidade do conflito ético, que se distingue tanto do niilismo (que simplesmente nega o ethos) como da ação eticamente má (que recusa a normatividade do ethos). O conflito ético é um conflito de valores e indica uma ruptura no processo de interiorização do ethos.

O nosso é um tempo de conflito, conflito ético; muitas são as possibilidades, difíceis são as escolhas. O nosso é um tempo em que a transmissão histórica de um modo de ser, de pensar e de agir encontra-se em crise, em decorrência das transformações valorativas ocorridas no percurso da civilização ocidental. As conquistas das tecnociências sintetizam os desafios das sociedades ocidentais contemporâneas: de um lado, anunciam-se possibilidades 'quase' ilimitadas de intervenção no curso da evolução natural dos seres vivos; de outro, reconhece-se que as matérias primas, indispensáveis para o funcionamento da engrenagem das sociedades industriais, acabam, não duram para sempre, ou seja, as possibilidades de exploração da natureza são limitadas.

\section{Pressupostos}

O presente ensaio foi estruturado a partir de uma visita feita à minha tese de doutoramento, que tem por título: A vida da ética: conhecimento, poder e ética no contexto das modernas biotecnologias (Cortes, 2001). Esse trabalho foi desenvolvido sob a perspectiva de ser a heteronomia a pedra angular da éti- 
ca e teve como uma de suas conclusões a interrogação: se as necessidades justificam as ações, qual seria então a razão de ser da ética?

Aqui importa destacar os seguintes pressupostos que balizam a estruturação deste ensaio. Primeiro, o entendimento de que toda e qualquer forma de compreensão e de comunicação da realidade apreendida indica diferentes formas de relação estabelecidas pelo homem com o mundo e com os seres que o cercam. Ou seja, conhecer é se relacionar. Relação como forma de conhecimento; conhecimento como uma forma de relação. Segundo, a vida é a razão e o propósito do empenho humano por conhecimento. A vida é fonte de pensamento, é instância última e primeira do motivo do conhecimento, como que, desde sua origem, o viver e o conhecer estivessem marcados por uma relação pactual. Por último, a hipótese de que certas intervenções que hoje se realizam no corpo humano só se tornaram possíveis porque a vida humana passou a ser olhada a partir de um determinado lugar; porque o valor da vida passou a ser julgado sob a ótica de determinados critérios.

Este ensaio não visa a apresentar um conjunto de teorias e conceitos que expliquem as concepções prevalecentes nas reflexões em torno do tema da ética. O que pretendemos é ressaltar que a trajetória tecida na história do Ocidente permitiu ao homem desvelar muitos dos 'mistérios da vida', tornando-se, nesse processo, cada vez mais poderoso e, acima de tudo, cioso do poder conquistado na ultrapassagem de limites. Um conjunto de eventos atesta o êxito da aposta dos homens na efetivação de um determinado padrão relacional com o mundo. A eficácia dos resultados confirma o êxito e atribui precedência a um dado caminho, dentre os diversos, do pensar e fazer humanos, um caminho cujos pressupostos e 'aprioris' foram tecidos sob a afirmativa da cisão entre fato e valor.

É evidente que vivemos hoje num mundo de opulências sem precedentes. O conforto e as facilidades, de compra, deslocamento, comunicação, o tempo médio de vida etc. são maiores que nunca. Mas, paralelamente, também vivemos num mundo de privação, destituição e opressão extraordinária. Um mundo em que uma parcela enorme da humanidade, nas palavras de Amartya Sen (2000), sofre a "privação de capacidades básicas"4. Este reconhecimento nos conduz à seguinte interrogação: no que diz respeito ao norte de nossas condutas e aos parâmetros de nossos julgamentos, que valores se tornaram obsoletos?

Qualquer tentativa de apresentar respostas a estas questões traz em si, mesmo que de forma oculta, um determinado entendimento sobre a vida e sobre o homem. Por conseguinte, por maior que seja a urgência de nos posicionarmos ante a necessidade de reconhecer a legalidade do uso dos conhecimentos acumulados pelas modernas tecnologias, não podemos nos furtar ao enfrentamento de velhas, novas, questões kantianas: O que é o homem? O que é a vida? O que fazer? Como fazer? Por que fazer? Na busca por res- 
postas, três autores têm destaque na construção deste trabalho: Martin Buber, Emmanuel Lévinas e Hans Jonas.

\section{Martin Buber: Eu e Tu}

Martin Buber nasceu em Viena, em 1878, morreu em Israel aos 87 anos em 13 de julho de 1965. Sua obra mais importante, Eu e Tu, é de 1921. Nesse trabalho, Buber identifica os caminhos que distinguem as possibilidades do homem se relacionar com o mundo, com os seres que nele habitam e com os outros homens: 'Eu-Tu' e 'Eu-Isso', são palavras-chave no seu pensamento5. Para Buber, 'Eu-Tu' e 'Eu-Isso' são dimensões constitutivas do homem; não se trata de uma questão de opção. 'Eu-Tu' e 'Eu-Isso' são caminhos, são modos pelos quais o homem se realiza no mundo. Não são possibilidades no sentido de que o homem possa abdicar, possa escolher viver exclusivamente em um destes dois mundos, possa decidir viver em acordo com um destes dois modos de relação. Buber (1979, p. 39) afirma que "o homem não pode viver sem o 'isso', mas o homem que vive somente com o 'isso' não é homem".

A tensão das possibilidades relacionais é constitutiva da vida de cada um de nós. O que não significa que a realidade seja fruto da minha (da sua) vontade. Mas, a partir da minha (da sua) liberdade, tenho responsabilidade pelo modo de relação de minha vida. O fato de 'eu saber alguma coisa' é sempre um salto para além de mim (Buber, 1985). Só 'sei', se consigo lograr essa ultrapassagem. Dizer 'eu sei' é ir além de mim, estabelecer um vínculo, uma ponte, uma relação. E, a partir da minha liberdade, eu posso definir os termos desse relacionamento.

Eu e Tu é uma obra que foi escrita num momento que alguns autores caracterizam como o momento da redescoberta do 'princípio dialógico'. Nos idos de 1920, Franz Rosenzweig e Gabriel Marcel, dentre outros, denunciaram em seus trabalhos o equívoco das apostas feitas tanto em direção ao individualismo possessivo, quanto em direção ao coletivismo impositivo. $\mathrm{O}$ princípio dialógico se funda na afirmação de que não é o sujeito a 'chance primordial do Ser', mas sim nossa vulnerabilidade à alteridade. Na perspectiva da antropologia filosófica de Buber, 'o Eu se torna Eu através do Tu', visto que o Eu não é solitário em sua origem. Não é a partir de sua solidão que o Eu organiza e compreende a realidade. Na origem está um encontro, e é a partir desse encontro que o Eu se torna Eu. Não é o encontro do Eu com ele mesmo; é um encontro com o Outro, com o que é diferente de mim. A relação não é entre iguais. É um encontro entre diferentes, não existe nenhuma garantia de reciprocidade. Mas é ouvindo, é prestando atenção no que é diferente de mim que posso ser tocado pelo sentimento da responsabilidadé6. 


\section{Emmanuel Lévinas: o humanismo do outro homem}

Emmanuel Lévinas nasceu na Lituânia em 1906, morreu em Paris em 1995. Em sua obra, estabelece um diálogo com toda a tradição do pensamento filosófico ocidental; ele não pretende menos do que colocar em xeque toda uma forma de pensar. Na revisita que faz à trajetória desse pensamento, pretende resgatar um pedaço constitutivo dessa civilização, um pedaço que, em acordo com seus argumentos, deliberadamente, foi esquecido pelo filosofar. Para Lévinas, somos marcados por uma dupla e, freqüentemente, contraditória fidelidade: aos filósofos e aos profetas. Mas, importante, ele não pretende conciliar as sabedorias grega e hebraica. Seu desejo é manter viva a tensão entre estes dois pólos da civilização ocidental. Para Lévinas, o logos é grego, mas o 'sentido' é hebraico.

“Há muito tempo, há tanto tempo, eu temia ter de dizer 'Adeus' a Emmanuel Lévinas" (Derrida, 2004, p. 11). Assim, Jacques Derrida iniciou um discurso pronunciado por ocasião da morte do pensador lituano-francês, em 27 de dezembro de 1995, no cemitério de Pantin, França. Nessa homenagem emocionada, o discípulo destaca que, anos depois de ter introduzido a fenomenologia em território francês, Lévinas foi responsável por promover o deslocamento no eixo da trajetória desse sistema de pensamento, realizando uma mutação na própria ordem da ontologia, abalando "uma vez mais, a paisagem sem paisagem do pensamento; ele o fez dignamente, sem polemizar, ao mesmo tempo do interior, fielmente, e de muito longe, a partir da afirmação de um lugar completamente diferente", produzindo:

\footnotetext{
“uma mutação discreta porém irreversível, uma dessas poderosas, singulares, raras provocações que, na história, depois de mais de dois mil anos, terão marcado indelevelmente o espaço e o corpo do que é mais ou menos, em todo caso outra coisa do que um simples diálogo entre o pensamento judaico e seus outros, as filosofias de ascendência grega ou, na tradição de um certo 'eis-me aqui', os outros monoteísmos abrâmicos" (Derrida, 2004, p. 27-28).
}

'Ousar saber é a mais soberana audácia': assim Emmanuel Lévinas descreveu o esforço do conhecimento humano. Em sua antropologia filosófica, a 'desconfiança de si' está na base do 'teorizar', e esta desconfiança decide sobre o sentido da teoria. A desconfiança de si pode se dar por dois motivos contrários e excludentes. Desconfiança a respeito de seus atos, considerando-os insuficientes e falhos - uma descoberta através de fracasso, que tem por objetivo a 'afirmação de si' — ou desconfiança que guia a teoria em direção a uma 'busca de justificação' para tornar-se 'certa'. O objetivo primeiro e último é moral, e o conhecimento visa à justificação na relação ao outro. A teoria exige então o reconhecimento de uma alteridade, e todo o ca- 
minho a percorrer procede da heteronomia, de um questionamento vindo da presença de um outro7.

Em convergência com Buber, Lévinas afirma que a 'preferência' do pensamento ocidental foi partir de um Eu separado, perseverando na ignorância do Outro e afirmando sua autonomia através da teoria. O pensamento ocidental se instaurou como um discurso que esqueceu o interlocutor, perdendo a dimensão da dialogicidade. Assim, o espírito crítico perverteuse na exacerbação do Eu soberano, que, ao se distanciar e olhar de fora, termina por construir a dissolução de seu próprio anonimato. Nesse movimento, o sujeito se instaura em máquina de processamento de informações. E nenhuma 'recordação crítica' 8 pode jamais minimizar as conseqüências desse percurso.

Ricardo Timm de Souza aponta para as graves implicações do percurso diagnosticado por Lévinas:

“parece ser cada vez maior a confusão entre aquele ser coletivo-cultural, genérico, a que se tem chamado tradicionalmente de humano, e suas infinitas expressões no mundo contemporâneo, os simulacros, as caricaturas, os infinitos substitutos que se apresentam em seu lugar, as infinitas mercadorias e sua glorificação em meio às quais o humano propriamente dito, precário em sua simplicidade irredutível a um algarismo, acaba por se perder, porque se perde a dimensão 'simples' de sua origem: sua irrepetibilidade. (...) A confusão com suas projeções e infinitos sentidos pelo qual pode o 'humano' ser compreendido, ou por cujo viés se pode dar a aproximação com esse espinhoso tema, desemboca geralmente no lugar comum do manuseio deliberado, econômico ou de outro teor, de sua substância mais íntima: mais uma vez, sua irrepetibilidade (...). E os tempos modernos e pós-modernos, esses tempos difíceis se especializaram nisso: em espezinhar e violentar essa irrepetibilidade" (Souza, 2000, p. 18).

Uma afirmativa fundamental na obra de Lévinas é que a diferença, a multiplicidade do real, está na raiz e origem da motivação do próprio conhecer. A partir desta perspectiva, sua obra vai apresentar um questionamento central: o da ontologia como 'filosofia primeira', pois "à teoria, como inteligência dos seres, convém o título geral de ontologia. A ontologia que reconduz o Outro ao Mesmo, promovendo a liberdade que é a identificação do Mesmo, que não se deixa alienar pelo Outro" (Lévinas, 1988, p. 30). Mas para Lévinas o discurso ontológico é incapaz de enxergar um 'fora de si', e estrutura uma apreensão da realidade onde o saber se instaura numa relação do Mesmo com o Outro em que o Outro é reduzido ao Mesmo e despojado de sua alteridade. Na lógica-linguagem ontológica reside, então, a raiz do egoísmo e da violência, características de uma civilização que se propôs a pensar e resolver o mundo desde a identidade e a identificação. 
Lévinas entende ser preciso operar uma ruptura na lógica identidadeser-totalidade estruturante do pensamento da civilização ocidental. Como ressalta Pergentino Pivatto, Lévinas afirma que:

“o método transcendental consiste sempre em procurar um fundamento. Uma idéia ou tese é justificada porque encontrou seu fundamento. Encontrar um fundamento é mostrar as condições de sua possibilidade, isto é, dar-se conta e dominar o encadeamento lógico que vai da base evidenciada até as últimas conseqüências. Esse método enaltece a ordem do ser, do poder, do saber e da correção objetivadora em que se anula a alteridade" (Pivatto, 2000, p. 83).

Lévinas aponta que o percurso civilizatório ocidental, já em sua origem, visa a reduzir ao mínimo a diferença, de modo que, como mostra Souza (2000, p. 123), “dos pré-socráticos a Heidegger, define o verdadeiro e o falso, o ser e o não-ser, o válido e o inválido, o real e o irreal, o racional e o irracional - dando sempre precedência ao primeiro termo dessas dualidades não apenas lógicas". Lévinas está em busca de um caminho que liberte o 'ser' do 'excesso de ser'. Esse caminho é uma travessia rumo a um outro lugar do pensamento, que se diferencia dos parâmetros da mensuração experimental que pavimentaram, no mundo ocidental, os caminhos do pensar. Como ressalta Souza (2000, p. 212), “a linguagem grega tem no verbo 'ser' sua essência mais profunda, o essencial de sua auto-compreensão. No verbo 'ser', cruzam-se todos os sentidos e suas possibilidades". Verbo que "é 'a referência das referências' (...) é ele que conecta os termos dispersos da realidade percebida e dá origem àquilo que temos chamado 'fórmula original do Ocidente': $[\mathrm{x}=\mathrm{y}]$ — onde a igualdade corresponde ao conectivo-explicativo "é', sempre no presente do indicativo".

É importante observar que a antropologia filosófica de raiz levinasiana distancia-se de qualquer concepção dualista do ser humano. Para Lévinas, o sujeito é sujeito sensório e só sensoriamente pode ser sujeito. Os homens, cada um de nós, somos uma unidade de corpo, alma, coração. A existência de cada um de nós não se realiza a partir do somatório de um conjunto de esferas distintas: intelectual, mental, instintiva, corpórea etc., tampouco a organização da cultura se deixa confundir com uma zeladoria do almoxarifado dos conceitos. Ela é primordial aos próprios conceitos. E a verdade existe imbricada no entrelaçamento corpóreo-anímico. A verdade e o empenho por compreendê-la são uma mesma coisa, que se instaura relacionalmente. Mas a relação não é um conceito, a relação é um 'vínculo', que me atinge, me toca, me fere. Na perspectiva levinasiana,

“A visão, por 'essência', estaria ligada ao corpo, dependeria do olho. 'Por essência', e não apenas 'de fato'. O olho não seria o instrumento mais ou menos aper- 
feiçoado pelo qual, na espécie humana, empiricamente, a operação ideal da visão alcançaria seu objetivo, captando, sem sombras e deformações, o reflexo do ser. E o fato da totalidade transpor o dado sensível, como o fato da visão ser encarnada, pertencem à essência da visão. Sua função original e última não consistiria em refletir o ser como num espelho. A receptividade da visão não deveria ser interpretada como uma aptidão a receber impressões" (Lévinas, 1993, p. 30).

O que Lévinas está dizendo é que toda a edificação do mundo cultural tem na relação vinculante seu ponto central. Nela, radica um encontro primordial do qual o conhecimento é fruto. A relação não é uma categoria abstrata, a relação se dá na existência real, concreta, corpórea. Não devemos perder de vista que, no percurso de Lévinas, a pergunta não é pelo ser, mas pelo sentido. Isto porque:

“Lévinas investiga nos horizontes que se abrem em torno das primeiras 'intenções' do dado abstrato a intriga humana - a relação entre eu e tu — que é a concretude de seu impensado, concretude que é o cenário indispensável do qual se desprenderam as abstrações traduzidas em palavras e enunciados. O escondido e secreto, por trás do cenário, é precisamente a relação inter-humana na qual Lévinas vê a textura da inteligibilidade última e a instauração do sentido humano, que o método transcendental negligencia" (Pivatto, 2000, p. 83).

Lévinas está em busca "não de um 'ser melhor', mas um 'melhor que ser"' (Susin, 1984, p. 195). Assim, na preferência do pensamento ocidental pela escolha de si mesmo, o que ocorreu foi uma dissociação entre 'coisa' e 'valor', entre epistemologia e ética. O que ocorreu foi a separação entre o ato de conhecer e o 'para quê se conhece'. O ponto de partida desta separação? Para Lévinas, foi o 'esquecimento do outro'. E este é um esquecimento que se dá antes de Descartes. O esquecimento do interlocutor é algo que está relacionado à trajetória da filosofia grega, é algo que está relacionado ao primado do logos no pensamento.

Conseqüência desta separação? A moral fica relegada a um corolário de uma filosofia. Uma filosofia que tem o Eu como centro de um movimento centrípeto. De tal modo que a moral pode ser quando muito uma 'moral de freio', diplomacias e concordatas entre os diversos Eus de uma sociedade. Qualquer observador mais perspicaz constatará que isto não é ética, é correlação de forças.

\section{Hans Jonas: o princípio da responsabilidade}

Hans Jonas nasceu em 1903 e morreu pouco antes de completar 90 anos, em 1993. Sua obra principal, o princípio da responsabilidade (1984), dedicada 
às questões éticas suscitadas pelo progresso da tecnologia ${ }^{9}$, tem também a característica de ser seu primeiro texto redigido em alemão após quase cinqüenta anos de formulação filosófica em língua não materna. Em que pese o fato de que Jonas dedicou grande parte de suas reflexões às questões urgentes do nosso tempo - aquelas relativas à civilização tecnocientífica -, com freqüência este pensador é visto como um filósofo 'tradicional'. Uma forma de entender esse tipo de enquadramento é dizer que, na contracorrente do espírito de sua época, Jonas insistiu obstinadamente nas antigas questões relativas ao homem, ao mundo e a Deus. Insistiu em abordar questões que hoje parecem não ter mais lugar ou valor, mas que continuam a nos comover, ainda que não sejamos capazes de explicar suas causas. Outro caminho de explicação para que seu pensamento seja enquadrado nos limites do tradicionalismo pode encontrar justificativa numa expressão do próprio Jonas, num dos capítulos de seu Philosophical essays: “Vivemos uma época de revolução" (Jonas, 1974). Para o filósofo, a ciência e a tecnologia estão no centro dessa revolução. Uma revolução que começou como um provinciano evento europeu e hoje é um acontecimento global. Ao longo de trezentos anos, remodelamos o mundo em que vivemos, remodelamos o modo de viver as nossas vidas, e por fim - ou, talvez, em primeiro lugar remodelamos nossa maneira de pensar ${ }^{10}$.

Antes deste livro, Jonas desenvolveu significativos trabalhos no campo da filosofia da biologia. Como pressuposto de argumentação deste empreendimento está a afirmativa de que a abordagem filosófica, que basicamente permanece através do idealismo (neokantiano, fenomenológico e existencialista) e que provém da vertente mecanicista-dualista, tinha se constituído na linha dominante da filosofia alemã. Essa abordagem, que separa da mente o corpo, produziu graves distorções no processo de compreensão do ser humano. Seria necessário, conseqüentemente, empreender a revisão do fundamento dualista em uma tarefa fundamental de crítica filosófica com vistas a elaborar uma filosofia integradora do ser humano. Em 1966, Jonas publicou O fenômeno da vida. Na origem de suas reflexões, empreende uma vigorosa crítica ao pensamento filosófico, para ele predominante no mundo ocidental, que conduziu ao entendimento de que o homem não é explicado a partir da natureza, mas, sim, extraído dela. Jonas termina por formular uma 'filosofia da biologia', em que a biologia se converte em ética. Ele entende a liberdade como condição ontológica de toda forma de vida 'animada'. E responsabilidade é a forma especificamente humana de exercício da liberdade. Através de sua interpretação filosófica da biologia moderna, Jonas combaterá a desvalorização niilista da natureza e o sentimento existencialista do abandono no mundo. Afirma que este dualismo foi o que levou ao esquecimento da natureza, marca da filosofia existencial. Afinal, quando se estabelece que a essência verdadeira do homem é a mente pensante, nada mais é 
necessário além da investigação de si mesmo, para se saber o que é; levar em conta a natureza e investigá-la tornam-se ações simplesmente dispensáveis. Em contraposição, Jonas julga ser necessário fundar uma biologia filosófica, que, por um lado, não despreze o conhecimento biológico acerca do homem, mas que, por outro, venha a acrescentar-lhe a dimensão de 'subjetividade do organismo'. Para o pensador, as grandes contradições que o homem descobre em si mesmo - liberdade e necessidade, autonomia e dependência, eu e o mundo, relação e isolamento, criatividade e mortalidade - estão pré-formadas já nas mais primitivas manifestações da vida. Cada uma destas mantém um equilíbrio muito perigoso entre o ser e o não ser. Na construção de sua filosofia da biologia, Jonas está preocupado em resgatar os vínculos do homem com a natureza, sem, no entanto, abdicar da dimensão especificamente humana, que se caracteriza pela construção do mundo cultural11.

Dos três autores que norteiam a argumentação deste ensaio, talvez Hans Jonas seja aquele cujo discurso manifeste de forma mais direta os desafios postos pela civilização tecnológica. Para ele, nossos 'modernos atos tecnológicos' traduzem a operação de uma mudança radical na natureza da ação humana. E visto que a ética diz respeito à ação, impõe-se, por conseqüência, a urgência de uma mudança na ética. Em relação aos princípios de todas as éticas preteritamente formuladas pela cultura ocidental, destaco dois aspectos que distinguem a proposta de Jonas: a ética para a civilização tecnológica não pode ser fundada em bases antropocêntricas e o horizonte de seus compromissos não pode estar restrito aos limites temporais da contemporaneidade.

Outro aspecto importante no 'princípio da responsabilidade' formulado por Jonas é a afirmativa de que, diante de nossos novos poderes, o conhecimento e a responsabilidade não podem estar divorciados da escala causal de nossas ações. O fundamento de sua argumentação reside no fato de que, aos seus olhos, estes nossos novos atos estão marcados por um inedistismo que diz respeito às possibilidades de suas conseqüências espaciais e temporais. Diante deste prognóstico, torna-se imperativo o seguinte reconhecimento: o 'conhecimento preditivo' sempre estará a alguns passos de distância do 'conhecimento tecnológico'. A impossibilidade de avaliação das conseqüências do desconhecido deve ser assumida como uma das variáveis do esforço humano na construção do conhecimento. Na perspectiva de Jonas, responsabilidade, entendida como responsabilidade pelo destino do homem, impõe precedência ao pior diagnóstico. A presença do homem no mundo era considerada como um dado primeiro e inquestionável, sobre o qual repousava a idéia de obrigação na conduta humana. Agora, nos lembra o filósofo, esta certeza ruiu. O que se pode vislumbrar como resultante desse exercício ilimitado da liberdade humana é a possibilidade do homo faber contemporâneo vir a, deliberadamente, privar um 'ser-humano-por-vir' de tal liberdade. Isto impõe, entre outras coisas, um dever para com a preservação de um 
mundo físico no qual estejam garantidas as condições para que aquela presença permaneça. No contexto da civilização tecnológica, impõe-se a obrigação de assegurar a verdadeira premissa de toda obrigação: a existência de meros 'candidatos' para a ordem moral.

Jonas coloca a responsabilidade no centro da ética e, de forma aguda, chama a atenção para o fato de que nossa geração é testemunha ocular de significativas transformações que extravasam o campo demarcado das ciências e tecnologias. Uso a expressão 'testemunha ocular' inspirada nos próprios escritos de Jonas. Penso que, em acordo com a perspectiva de seu pensamento, podemos dizer que testemunhas oculares são testemunhas de acontecimentos dos quais têm notícia não por ouvir dizer, não são testemunhas de idéias que têm a potencialidade de se transformarem em realidade, tampouco são testemunhas da lembrança de fatos ou catástrofes ocorridas num passado longínquo. São testemunhas que, pelo simples fato de presenciarem determinados acontecimentos, têm posta sobre elas, sobre nós, a responsabilidade pelas conseqüências destas transformações, destas idéias-ato. Tênues passam a ser as distâncias entre intenção e gesto no contexto das modernas biotecnologias. É a partir desta referência que Jonas estabelece como imperativo categórico de uma ética da responsabilidade o alerta: que haja uma humanidade! Ele está nos falando sobre a possibilidade da perda da unidade, não mais no sentido simbólico, mas no sentido material, disso que até então chamamos de 'humanidade'.

É nos vínculos do homem com a natureza que vai buscar o arquétipo de toda ação responsável: a responsabilidade pelo recém-nascido - uma responsabilidade instituída pela natureza, independente de qualquer acordo prévio. Diante do recém-nascido, a responsabilidade é incondicional e nãorecíproca. Nas palavras de Roberto Bartholo:

\footnotetext{
“Sua simples existência nos chama à responsabilidade. Nosso poder total sobre o recém-nascido engendra uma responsabilidade total, onde qualquer pretensão de neutralidade ética é impossível e a mera omissão já seria fatal para esta existência diante da possibilidade da morte. O recém-nascido é a expressão de um 'apelo do Ser', que nos comove os sentimentos e nos impõe o reconhecimento de devermos fazer desta auto-afirmação do Ser nosso esforço, de modo que 'o imanente 'Dever-Ser' do recém-nascido, que se anuncia a cada respiração, se torna o transitivo 'Dever-Fazer' de outros'” (Bartholo, 1986, p.113).
}

Hans Jonas destaca que toda atenção da ética corrente na modernidade ocidental focava-se na qualidade moral do ato presente e na delimitação de seus efeitos sobre 'os próximos', segundo o princípio da reciprocidade. A proximidade dos fins era válida tanto para o tempo quanto para o espaço. Estando os atos demarcados ao tempo presente, estabelecia-se como certo que são 
aqueles que agora estão vivos e mantêm algum tipo de convívio comigo os que podem reivindicar algo a mim e ao meu comportamento, na medida em que são afetados pelo meu agir ou por minha omissão. Assim sendo, o universo moral era formado por nossos contemporâneos, e seu horizonte futuro limitava-se ao seu tempo de vida presumível. O mesmo ocorria em relação ao horizonte espacial, em que o agente e o outro se encontravam na qualidade de vizinhos, amigos ou inimigos, superiores ou subalternos, mais fortes e mais fracos, e em todos os demais papéis que os homens assumiam em seu convívio. Toda moralidade estava focalizada neste círculo próximo do agir. Essa situação torna-se insustentável quando a técnica contemporânea inaugura uma era em que os atos possuem um inusitado alcance causal no futuro, uma ordem planetária de efeitos e freqüente irreversibilidade. O poder de alcance das ações humanas no contexto da tecnologia moderna impede que continuemos conduzindo nossos atos sob a afirmativa da 'neutralidade ética da técnica', afirmativa sob a qual se abrigavam todas as técnicas precedentes, tanto em relação ao sujeito quanto ao objeto.

Conforme destacamos, para Jonas, responsabilidade é sinônimo de responsabilizarmo-nos pelo destino do homem. Na perspectiva em que formula seu princípio, esta responsabilidade não se restringe à esfera do sujeito individual, ela se refere à praxis coletiva e impõe novos deveres aos agentes políticos. Seu primeiro reconhecimento é que o saber, o ato de conhecer, sob as condições de nossas contemporâneas circunstâncias, assume, como nunca antes, a importância de ser nosso primeiro dever. Jonas entende que precisamos admitir o fato que, 'de fato', não temos como asseverar todas as possíveis conseqüências de uma determinada forma de conhecimento. O reconhecimento de que existe uma distância entre o conhecimento tecnológico e a nossa capacidade para prognosticar cria um novo problema moral. É exatamente nesse espaço que o conhecimento assume importância ética.

Reconhecer nossa ignorância é reconhecer um limite. Mas Jonas entende que este reconhecimento deve ser incorporado aos limites das próprias possibilidades do conhecer. A ignorância e a impossibilidade de avaliação das 'conseqüências do desconhecido' devem ser assumidas como variáveis do esforço humano na construção do conhecimento. O desconhecido é a contraface do dever de saber.

É preciso ressaltar que, para Jonas, o que está em discussão não é em absoluto uma pretensa falsidade da forma científica de conhecimento. Introduzir a variável responsabilidade no centro da avaliação das conseqüências de nossos modernos atos tecnológicos requer um acervo de conhecimentos e de habilidades de ação para a implementação de processos tecnicamente viáveis e eticamente desejáveis. Para o filósofo, as implicações dos nossos modernos caminhos de conhecer-interferir na realidade, de forma inédita, exigem a assunção de perspectivas de longo prazo, numa visão de futuro 
onde se fazem presentes a incerteza e a surpresa. A estratégia de ação deve buscar assegurar uma razoável gama de opções para haver uma desejável flexibilidade de resposta. Isso requer o fortalecimento da base científica e de pesquisa, a prudente interação entre as ciências e a tomada de decisões. Como decorrência da transformação da essência do agir humano, impõe-se a transformação da essência da política.

O lugar da ética é o lugar da concordância de que 'alguma coisa' não deve ser transgredida. Inevitável admitir que tal concordância está impregnada de uma dimensão valorativa. A ética não pode ser entendida como um adendo, um adereço que acrescentamos a posteriori. Essa dimensão valorativa está presente na origem mesma de nossas ações. O que podemos, sim (e é o que com freqüência ocorre), no esquecimento da antecedência destes valores, é só reconhecer, a posteriori, que determinados valores foram transgredidos. Concordar com esse entendimento implica aceitar que só por esquecimento ignoramos as relações existentes entre a ética e o conhecimento.

\section{À guisa de conclusão}

É fato que existem, em muitos aspectos, diferenças entre as obras de Martin Buber, Emmanuel Lévinas e Hans Jonas, mesmo que estas diferenças, por vezes, sejam sutis. Mas os três, além da longevidade e do fato de serem judeus - o que, em se tratando de pessoas que realizaram suas existências no curso do século XX, é sinônimo de ser sobrevivente - , convergem em alguns entendimentos fundamentais que estruturam nossos argumentos.

Primeiro, o reconhecimento de que a ciência delineia o arcabouço de nossa moderna cosmovisão. Foi sob a sua ótica, seus parâmetros e critérios que nos últimos séculos 'treinamos nosso olhar' para os fenômenos que nos cercam, de tal forma que não poucas vezes acabamos por aprisionar esses fenômenos nos limites dos conceitos por nós construídos. A dimensão dos poderes humanos alcançados pelo pensar-fazer-técnico-científico tornou factíveis intervenções até então demarcadas no âmbito da ficção científica. Diante de nossos novos poderes, muitos são os desafios. Diante dos desafios, o que perguntamos é se perdemos a disposição para 'pular o muro'12 que construímos para demarcar nossa visão de mundo. Buber, Lévinas e Jonas pulam o muro. Não temem transitar nas fronteiras que demarcam as diversas possibilidades do pensar. Os três buscam reconectar o pensar e o fazer humanos com o sentido desse agir. No ponto de partida e de chegada de suas reflexões, a vida humana é afirmada como o valor mais alto. As obras desses autores, no tanto que nos relembram, reavivam o pacto que funda e motiva a relação entre a vida e o conhecimento.

Há um segundo aspecto importante, que apresentamos como interrogação: se as necessidades justificam as ações, qual seria então a razão de ser 
da ética? Os três filósofos compartilham a perspectiva de ser a heteronomia a pedra angular da ética. Mas, diferentemente de Kant, na base de suas formulações não está a vontade do homem. Buber, Lévinas e Jonas afirmam o 'primado do outro' como fundamento da ética. Nesse aspecto, chegam a ser cruéis; não nos permitem confundir ética com discursos ou respostas que não vão além do horizonte da auto-justificação. Entendem que a ética é o reconhecimento de limites; assim sendo, cabe indagar qual o papel que ela cumprirá se não estiver fundada sobre a primazia do outro. A presença do outro, do que é diferente de mim, desencadeia o movimento do pensar e inaugura o agir ético.

Podemos destacar um terceiro ponto de convergência entre Buber, Lévinas e Jonas: a presença do outro demarca um limite, ao mesmo tempo em que impõe a manifestação de uma resposta. A responsabilidade, na perspectiva dos três autores, é sinônimo de resposta a esta presença. A possibilidade de não responder pode ser entendida como parte do exercício da liberdade humana. Mas, para eles, responder ao apelo invocado pela presença de uma alteridade não limita, ao contrário, é o que promove a liberdade humana.

Acatar a responsabilidade pelo outro é o caminho, é uma espécie de convite a que nos libertemos da 'mesmice' implicada no 'sermos para nós mesmos'. Reconhecer que a presença do outro demarca um limite ao exercício de uma liberdade fundada na vontade do Eu liberta esse mesmo Eu para receber aquele que é diferente de mim. Poderíamos mesmo dizer que 'responder ao apelo da presença do que é diferente de mim' é uma espécie de antídoto à neutralização, que é marca constitutiva do entendimento de que responsabilidade é uma espécie de subproduto da vontade de um Eu, solitário e autônomo. Para Buber, Lévinas e Jonas, esse Eu, solitário e autônomo, é que é produto de um pensamento ficcional, de um pensamento desvinculado da realidade da vida humana.

Por último, fazemos o registro do seguinte reconhecimento: as reflexões filosóficas, científicas, jurídicas, etc, no que se refere ao ineditismo das possibilidades, e respectivas conseqüências, inauguradas pelo conhecimento científico, não têm sido formuladas em sintonia com as 'provocações' feitas pelos autores que fundamentaram a construção deste nosso breve ensaio. Não existe consenso quanto ao reconhecimento de que, nas fronteiras que têm sido desbravadas por este 'modo de conhecer', determinados valores podem estar sendo transgredidos. Todavia, por entender que estamos falando de intervenções que se tornaram possíveis porque a vida está sendo olhada a partir de um determinado lugar, por entender que a vida humana está sendo avaliada sob a ótica de determinados valores, acreditamos ser pertinente 'escutar' o que nos dizem Martin Buber, Emmanuel Lévinas e Hans Jonas.

Entendemos que o que está em questão é 'o valor e o sentido da vida humana'. De que não podemos abrir mão? Da defesa de que a ética deve ser 
construída a partir da valoração da vida. Não podemos escamotear a verdade de que 'aprioris' valorativos são condição necessária à ética. O primeiro desafio não é a negação ou a desqualificação do discurso da razão, mas o reconhecimento de que este discurso precisa ser submetido a juízos, a critérios, a uma hierarquização do valor. É uma conclamação à defesa do discurso da 'razão submissa'.

\section{Notas}

1 Pesquisadora Adjunta da Casa de Oswaldo Cruz, Fundação Oswaldo Cruz (COC/Fiocruz). Doutora em Ciências pela Universidade Federal do Rio de Janeiro. <bcortes@coc.fiocruz.br>

2 Sobre as transformações que se processaram nesses conceitos a partir da segunda metade do século XX, ver Bernard (1990).

3 Respeito é "reverência, veneração, obediência", conforme nos afirma Antônio Geraldo da Cunha (1982, p. 679). Mas, como observa Erich Fromm (2000, p. 35), esses significados não nos permitem estabelecer nenhuma correspondência com o sentimento de medo ou de temor. "Respeito não é medo e temor reverente; ele denota, conforme a própria raiz da palavra (respicere = olhar com atenção), a capacidade de ver uma pessoa como ela é, ter consciência de sua individualidade. Respeito significa a preocupação com que o outro cresça e se desenvolva tal como ele é. Respeito implica, portanto, ausência de exploração".

4 Amartya Sen entende que a vida de uma pessoa pode ser concebida como um conjunto de 'capacidades básicas'. O exercício dessas capacidades indica a qualidade de vida de uma pessoa e tem uma relação direta com a liberdade individual. Cabe destacar que para este autor "é importante o reconhecimento simultâneo da centralidade da liberdade individual e da força das influências sociais sobre o grau e o alcance da liberdade individual" (Sen, 2000, p. 53). Assim, a privação de capacidades básicas traduz a ausência de liberdades substantivas, as quais podem estar relacionadas, por exemplo, com a pobreza econômica, a carência de serviços públicos e assistência social, ou a negação de liberdades políticas e civis. O exercício dessas liberdades ajuda a promover as capacidades básicas de uma pessoa.

5 No Brasil, a tradução de Eu e Tu, título do livro mais importante de Martin Buber, foi feita por Newton Aquiles von Zuben. Nessa tradução, a expressão 'Eu-Tu' aparece em caixa alta ('EU-TU'). No presente texto, dispensamos o uso da caixa alta, mas mantivemos as iniciais maiúsculas (N. do E.).

6 Sobre o pensamento de Martin Buber, ver Bartholo (2001). 
7 Luiz Carlos Susin realizou um primoroso trabalho de reconstrução da trajetória do pensamento de Emmanuel Lévinas (Susin, 1984).

8 'Recordação crítica' é uma expressão utilizada por Lévinas (1988) para definir o ato de filosofar.

9 Sobre as inter-relações que se estabelecem entre o 'princípio da responsabilidade' formulado por Hans Jonas e a prática de produção dos conhecimentos científicos, ver Bartholo (1986), Cortes (1998), Giacoia (2000).

10 Sobre esta passagem da obra de Jonas, ver Cortes (2002).

11 Aldo Medeiros Bonifácio (1997) fez um bonito trabalho sobre a trajetória do pensamento de Hans Jonas. Não só por seu mérito, esse registro ganha destaque se considerarmos o fato de que poucos escritos de Jonas foram traduzidos para a língua portuguesa. Cabe registrar que Roberto Bartholo (1986), com a tradução de sua tese de doutoramento, provavelmente se enquadra na 'categoria' dos introdutores do pensamento de Hans Jonas no Brasil. Mais recentemente, destaca-se o trabalho de Oswaldo Giacoia Jr (2000).

12 A idéia de que o 'mundo da cultura' é uma construção humana, cujas marcas de diversidade podem ser identificadas nas diferentes formas de percepção do mundo que nos cerca, aqui foi inspirada no livro O homem revoltado, de Albert Camus (1996). "Em tanto que verdadeiro o fato de que a ciência delineia o arcabouço de nossa 'cosmovisão', o que se pergunta é se perdemos a disposição para 'pular o muro' que construímos para demarcar nossa visão de mundo. A dúvida é se tal perda de disposição se deve ao fato de definitivamente termos encontrado um abrigo suficientemente aconchegante, ou, se não acreditamos mais na existência de tal aconchego. O homem perdeu a capacidade de se 'revoltar'?" (Cortes, 2001, p. 3). O que é um 'homem revoltado'? Para Camus (1996, p. 25), "um homem que diz não. Mas, se ele recusa, não renuncia: é também um homem que diz sim, desde o seu primeiro movimento. Um escravo, que recebeu ordens durante toda a sua vida, julga subitamente inaceitável um novo comando. Qual o significado deste 'não'? Significa, por exemplo, 'as coisas já duraram demais', 'até aí sim; a partir daí, não'; 'assim já é demais', e, ainda 'há um limite que você não vai ultrapassar'. Em suma, este 'não' (grifo nosso) afirma a existência de uma fronteira".

\section{Referências}

ARENDT, Hannah. 1991. A condição humana. $5^{\mathrm{a}}$ ed. Rio de Janeiro: Forense Universitária.

BARTHOLO, Roberto. 1986. A ética da responsabilidade e o poder científico-tecnológico moderno. In: BARTHOLO, Roberto. Os labirintos do silêncio: cosmovisão e tecnologia na modernidade. São Paulo: Marco Zero, p. 104-115.
_. 2001. Você e eu. Rio de Janeiro: Garamond.

BERNARD, Jean. 1990. Da biologia à ética: novos poderes da ciência, novos deveres dos Homens. Portugal: Publicações Europa.

BONIFÁCIO, Aldo M. 1997. Atualidade do pensamento de Hans Jonas: uma introdução ao princípio da responsabilidade. 
Dissertação de Mestrado, Rio de Janeiro: Coordenação de Programas de PósGraduação em Engenharia, Universidade Federal do Rio de Janeiro.

BUBER, Martin. 1979. Eu e tu. São Paulo: Cortez \& Moraes.

1985. ¿Que es el hombre? México: Fundo de Cultura.

CAMUS, Albert. 1996. O homem revoltado. $2^{a}$ ed. Rio de Janeiro-São Paulo: Record.

CORTES, Bianca A. 1998. 'Responsabilidade': um imperativo para a discussão do que hacer científico. Ciência \& Saúde Coletiva, v. 3, n. 2, p. 17-18.

.2001. A vida da ética: conhecimento, poder e ética no contexto das modernas biotecnologias. Tese de Doutorado, Rio de Janeiro: Coordenação de Programas de Pós-Graduação em Engenharia, Universidade Federal do Rio de Janeiro. .2002. A ética da responsabilidade: um desafio às relações entre conhecimento, poder e ética. In: BARTHOLO, Roberto et al. (orgs.). Ética e sustentabilidade. Rio de Janeiro: E-papers, p. 19-31.

CUNHA, Antônio G. da. 1982. Dicionário Etimológico: nova fronteira da língua portuguesa. Rio de Janeiro: Nova Fronteira.

DERRIDA, Jacques. 2004. Adeus a Emmanuel Lévinas. São Paulo: Perspectiva.

FROMM, Erich. 2000. A arte de amar. São Paulo: Martins Fontes.

GIACOIA JR, Oswaldo. 2000. Hans Jonas: o princípio da responsabilidade. Ensaio de uma ética para uma civilização tecnológica. In: OLIVEIRA, Manfredo A. de (org.). Correntes fundamentais da ética contemporânea. Petrópolis: Vozes, p. 193-206.
JONAS, Hans. 1966. The phenomenon of life: toward a philosophical biology. ChicagoLondon: The University of Chicago Press. 1974. Seventeenth century and after: the meaning of the scientific and technological revolution. In: JONAS, Hans. Philosophical essays: from ancient creed to tecnological men. Chicago-London: The University Chicago Press, p. 45-80. 1984. The imperative of responsability: in search of an ethics for the technological age. Chicago-London: The University of Chicago Press.

LÉVINAS, Emmanuel. 1988. Totalidade e infinito. Lisboa: Edições 70.

1993. Humanismo do outro homem. Petrópolis: Vozes.

PIVATTO, Pergentino S. 2000. Ética da alteridade. In: MANFREDO, A. de Oliveira (org.). Correntes fundamentais da ética contemporânea. Petrópolis: Vozes, p.79-97.

SEN, Amartya. 2000. Desenvolvimento como liberdade. São Paulo: Companhia das Letras.

SOUZA, Ricardo T. de. 2000. Sentido e alteridade: dez ensaios sobre o pensamento de Emmanuel Lévinas. Porto Alegre: EDIPUCRS

SUSIN, Luiz Carlos. 1984. O homem messiânico: uma introdução ao pensamento de Emmanuel Lévinas. Petrópolis/Porto Alegre: Vozes/Escola Superior de Teologia São Lourenço de Brindes.

VAZ, Henrique Cláudio de L. 1998. Escritos de filosofia II: ética e cultura. São Paulo: Loyola.

Recebido em 10/11/2004

Aprovado em 05/01/2005 